\title{
PENDUGAAN PARAMETER PADA DISTRIBUSI GAMMA DENGAN METODE BAYES
}

\author{
USWATUL HASANAH, FERRA YANUAR, DODI DEVIANTO \\ Program Studi Matematika, \\ Fakultas Matematika dan Ilmu Pengetahuan Alam, Universitas Andalas, \\ Kampus UNAND Limau Manis Padang, Indonesia, \\ email : uswatulhasanah276@gmail.com
}

\begin{abstract}
Abstrak. Penelitian ini membahas tentang pendugaan parameter pada distribusi Gamma dengan parameter $\alpha$ diketahui. Metode pendugaan parameter yang digunakan adalah metode Bayes dengan dua distribusi prior, yaitu distribusi prior konjugat dan distribusi prior non-informatif. Distribusi prior konjugat yang diperoleh adalah distribusi Gamma $\left(\alpha^{\prime}, \beta^{\prime}\right)$ dan distribusi prior non-informatif diperoleh dengan melakukan metode perluasan Jeffrey sehingga menghasilkan prior Jeffrey adalah $\frac{1}{\beta^{2 k}}$.
\end{abstract}

Kata Kunci: Metode Bayes, Distribusi prior, Metode Jeffrey, Distribusi Gamma

$\begin{array}{lll}\text { Diterima } & : & 29 \text { November } 2018 \\ \text { Direvisi } & : & 3 \text { Desember } 2018 \\ \text { Dipublikasikan } & : & 30 \text { Desember } 2018\end{array}$

\section{Pendahuluan}

Statistika inferensia terbagi atas dua, yaitu pendugaan parameter dan pengujian hipotesis. Pendugaan parameter dilakukan untuk menduga nilai parameter suatu populasi yang menjadi perhatian penelitian [9]. Pendugaan parameter terbagi atas dua, yaitu penduga titik dan penduga selang. Pendugaan parameter dapat dilakukan dengan metode Maximum Likelihood Estimation, metode momen, metode Kuadrat Terkecil, dan metode Bayes. Metode Bayes merupakan metode yang menggabungkan distribusi sampel dengan distribusi prior. Distribusi prior adalah distribusi awal dari suatu parameter yang memberikan informasi [7]. Penggabungan inilah yang akan membentuk distribusi baru yang disebut dengan distribusi posterior [6].

Hasil pendugaan dengan metode Bayes Hasil pendugaan dengan metode Bayes ini biasanya menghasilkan nilai duga yang lebih hampir dan lebih baik dari pada metode Klasik (metode Momen, metode MLE, dan lain-lain) [11]. Inferensi akan lebih bagus jika data yang digunakan adalah data gabungan antara data sampel dengan data penelitian sebelumnya (data prior) [2]. 


\section{Landasan Teori}

\subsection{Fungsi Likelihood}

Suatu peubah acak $X_{1}, X_{2}, \cdots, X_{n}$ dapat ditentukan fungsi likelihoodnya yang dinyatakan sebagai $f(x \mid \theta)$.

Definisi 2.1. [3] Fungsi kepekatan peluang bersama dari $n$ peubah acak $X_{1}, X_{2}, \cdots, X_{n}$, yang dihitung pada $x_{1}, x_{2}, \cdots, x_{n}$ dinyatakan dalam bentuk $f\left(x_{1}, x_{2}, \cdots, x_{n} ; \theta\right)$ dikatakan sebagai fungsi likelihood. Untuk $x_{1}, x_{2}, \cdots, x_{n}$ maka fungsi likelihood dari $\theta$ yang dinotasikan dengan $f(x \mid \theta)$. Jika $X_{1}, X_{2}, \cdots, X_{n}$ merupakan contoh acak dari $f(x ; \theta)$, maka:

$$
f(x \mid \theta)=f\left(x_{1} ; \theta\right), \cdots, f\left(x_{n} ; \theta\right)=\Pi_{i=1}^{n} f\left(x_{i} ; \theta\right) .
$$

\subsection{Distribusi Prior dan Distribusi Posterior}

Distribusi prior merupakan distribusi awal dari suatu parameter yang memberikan informasi sebelum mencari distribusi posterior.

Definisi 2.2. [3] Distribusi Posterior Fungsi kepekatan peluang bersyarat dari $\theta$ jika diketahui pengamatan sampel $x=x_{1}, x_{2}, \cdots, x_{n}$ disebut fungsi kepekatan peluang posterior, yang diberikan oleh

$$
f(x \mid \theta)=\frac{f(x \mid \theta) f(\theta)}{\int_{-\infty}^{\infty} f(x \mid \theta) f(\theta) d \theta} .
$$

Penyebut $\int_{-\infty}^{\infty} f(x \mid \theta) f(\theta) d \theta$ akan menghasilkan fungsi kepekatan peluang marginal untuk $x$ ditulis dengan $f(x)$. Karena $f(x)$ tidak bergantung dengan parameter sehingga nilainya cendrung konstan, maka persamaan (2.2) dapat ditulis dengan

$$
f(x \mid \theta) \propto f(x \mid \theta) f(\theta)
$$

dengan $f(x \mid \theta)$ adalah fungsi likelihood dan $f \theta)$ adalah distribusi prior [5].

Definisi 2.3. [10] Penduga Bayes Nilai tengah dari distribusi posterior $f\left(\theta \mid x_{1}, x_{2}, \cdots, x_{n}\right)$ dinyatakan dengan $\theta^{*}$, disebut penduga Bayes untuk $\theta$.

\subsection{Metode Jeffrey}

Untuk mencari distribusi prior non-informatif suatu peubah acak dapat dilakukan dengan melakukan pendekatan metode Jeffrey. Prior perluasan Jeffrey $f(\beta)$ biasa diperoleh dari [1]:

$$
f(\beta) \propto[I(\beta)]^{k}, \text { untuk } k \in R^{+},
$$

dengan $I(\beta)$ adalah informasi Fisher yang diperoleh dengan menggunakan rumus $I(\beta)=-n E\left\{\frac{\partial^{2}}{\partial \beta^{2}} \ln f(x \mid \beta)\right\}$ dan $f(x \mid \beta)$ adalah fungsi likelihood. 


\subsection{Distribusi Gamma}

Distribusi Gamma merupakan salah satu distribusi dari peubah acak kontinu. Definisi untuk distribusi Gamma adalah sebagai berikut:

Definisi 2.4. [4] Misalkan X suatu peubah acak kontinu berdistribusi Gamma dengan parameter $\alpha>0$ dan $\beta>0$, maka bentuk fungsi kepekatan peluangnya adalah

$$
f(x ; \alpha, \beta)=\frac{(\beta)^{\alpha} x^{\alpha-1} \exp (-x(\beta))}{\Gamma(\alpha)}, \text { untuk } x \geq 0 .
$$

Jika $\mathrm{X}$ berdistribusi Gamma, ditulis $X \sim \operatorname{GAM}(\alpha, \beta)$ maka nilai tengah dan variansi distribusi Gamma adalah

$$
\mu=E(X)=\frac{\alpha}{\beta}, \text { dan } \sigma^{2}=\operatorname{var}(X)=\frac{\alpha}{\beta^{2}} .
$$

\section{Pembahasan}

\subsection{Fungsi Likelihood dan Distribusi Prior}

Jika diketahui $X_{1}, X_{2}, \cdots, X_{n}$ adalah peubah acak berdistribusi Gamma dengan parameter $\alpha$ dan $\beta$, atau ditulis $X_{i} \sim G A M(\alpha, \beta)$, fungsi likelihood, seperti berikut:

$$
\begin{aligned}
f(x \mid \beta) & =\prod_{i=1}^{n} f\left(x_{i} ; \beta\right) \\
& =\prod_{i=1}^{n} \frac{\beta^{\alpha} x_{i}^{\alpha-1} \exp \left(-\beta x_{i}\right)}{\Gamma(\alpha)} \\
& =\left(\beta^{\alpha}\right)^{n}(\Gamma(\alpha))^{-n}\left(\prod_{i=1}^{n} x_{i}^{\alpha-1}\right) \exp \left(-\beta \sum_{i=1}^{n} x_{i}\right) \\
& \propto \beta^{n \alpha} \exp \left(-\beta \sum_{i=1}^{n} x_{i}\right) .
\end{aligned}
$$

\subsubsection{Distribusi prior konjugat}

Bentuk fungsi likelihood dari data yang berdistribusi $\operatorname{Gamma}(\alpha, \beta)$ memiliki kesamaan bentuk atau dapat dikatakan proposional dengan fungsi kepekatan peluang dari suatu peubah acak yang berdistribusi $\operatorname{Gamma}\left(\alpha^{\prime}, \beta^{\prime}\right)$, yaitu:

$$
f(\beta) \propto \beta^{\alpha^{\prime}-1} \exp \left(-\beta\left(\beta^{\prime}\right)\right) .
$$

Persamaan (3.1) kemudian dimodifikasi sehingga menjadi bentuk berikut:

$$
f(x \mid \beta) \propto \beta^{(n \alpha+1)-1} \exp \left(-\beta \sum_{i=1}^{n} x_{i}\right) .
$$

Persamaan (3.3) tersebut merupakan fungsi kepekatan peluang dari distribusi Gamma dengan parameter $\alpha^{\prime}=n \alpha+1$ dan $\beta^{\prime}=\sum_{i=1}^{n} x_{i}$, atau dapat dinotasikan dengan $\beta \sim \operatorname{GAM}\left(n \alpha+1, \sum_{i=1}^{n} x_{i}\right)$. 
84 Uswatul Hasanah dkk

\subsubsection{Distribusi Prior Non-informatif}

Misalkan peubah acak $\delta$ yang beranggotakan $\alpha$ dan $\beta$ yang saling bebas atau dapat ditulis $\delta=(\alpha, \beta)$. Pada bagian ini kita menggunakan distribusi Gamma dengan $\alpha$ diketahui atau dapat dikatakan bahwa $\alpha$ suatu konstanta maka diperoleh $f(\alpha)=c$ untuk suatu c adalah konstanta.

$$
\begin{aligned}
\ln (f(x \mid \beta)) & \propto n \alpha \ln (\beta)-\beta \sum_{i=1}^{n} x_{i}, \\
\frac{\partial}{\partial \beta} \ln (f(x \mid \beta)) & \propto \frac{n \alpha}{\beta}-\sum_{i=1}^{n} x_{i}, \\
\frac{\partial^{2}}{\partial \beta^{2}} \ln (f(x \mid \beta)) & \propto \frac{n \alpha}{\beta^{2}}, \\
I(\beta) & =-n E\left\{\frac{\partial^{2}}{\partial \beta^{2}} \ln (f(x \mid \beta))\right\}=-\frac{n^{2} \alpha}{\beta^{2}}
\end{aligned}
$$

sehingga diperoleh prior perluasan Jeffrey adalah

$$
f(\beta) \propto[I(\beta)]^{k} \propto\left[-\frac{n^{2} \alpha}{\beta^{2}}\right]^{k} \propto \frac{1}{\beta^{2 k}}
$$

untuk $k \in R^{+}$dan $\beta>0$. Selanjutnya akan dicari distribusi non-informatif untuk $f(\delta)$ yaitu :

$$
\begin{aligned}
f(\delta) & =f(\alpha, \beta)=f(\alpha) f(\beta) \\
& =c \times \frac{1}{\beta^{2 k}} \\
& =\frac{c}{\beta^{2 k}} \propto \frac{1}{\beta^{2 k}} .
\end{aligned}
$$

\subsection{Penentuan Distribusi Posterior}

3.2.1. Distribusi Posterior dari Distribusi Prior Konjugat

Distribusi posterior untuk distribusi prior konjugat

$$
\begin{aligned}
f(\beta \mid x) & \propto f(\beta) \times f(x \mid \beta), \\
& \propto \beta^{n \alpha+\alpha^{\prime}-1} \exp \left(-\beta\left(\left(\beta^{\prime}\right)+\sum_{i=1}^{n} x_{i}\right)\right) .
\end{aligned}
$$

Persamaan (3.5) merupakan fungsi kepekatan peluang dari distribusi $\operatorname{Gamma}\left(\alpha^{\prime \prime}, \beta^{\prime \prime}\right)$ dengan $\alpha^{\prime \prime}=n \alpha+\alpha^{\prime} \operatorname{dan} \beta^{\prime \prime}=\beta^{\prime}+\sum_{i=1}^{n} x_{i}$ atau dinotasikan dengan:

$$
\beta_{1} \mid X \sim G A M\left(n \alpha+\alpha^{\prime}, \beta^{\prime}+\sum_{i=1}^{n} x_{i}\right)
$$


3.2.2. Distribusi Posterior dari Distribusi Prior Non-informatif

$$
\begin{aligned}
f(\delta \mid x) & \propto f(\delta) \times f(x \mid \delta) \\
& \propto \beta^{n \alpha-2 k+1-1} \exp \left(-\beta \sum_{i=1}^{n} x_{i}\right) .
\end{aligned}
$$

Distribusi posterior dari $\delta$ atau ditulis dengan $f(\delta \mid x)=f(\alpha, \delta \mid x) \propto f(\alpha \mid x) \propto f(\beta \mid x)$ [8], sehingga diperoleh distribusi posterior untuk $\beta$ adalah

$$
f(\beta \mid x) \propto \beta^{n \alpha-2 k+1-1} \exp \left(-\beta \sum_{i=1}^{n} x_{i}\right) .
$$

Persamaan (3.8) adalah fungsi kepekatan peluang dari distribusi Gamma dengan parameter $\alpha^{\prime}=n \alpha-2 k+1, \beta^{\prime}=\sum_{i=1}^{n} x_{i}$, atau dapat ditulis dengan

$$
\beta_{2} \mid X \sim G A M\left(n \alpha-2 k+1, \sum_{i=1}^{n} x_{i}\right) .
$$

\subsection{Posterior Nilai Tengah dan Posterior Variansi}

3.3.1. Posterior nilai tengah dan posterior variansi dari distribusi prior konjugat

Dari distribusi posterior $\beta_{1} \mid X \sim G A M\left(n \alpha+\alpha^{\prime}, \beta^{\prime}+\sum_{i=1}^{n} x_{i}\right)$, maka posterior nilai tengah dan posterior variansi untuk parameter $\beta_{1}$ adalah

$$
\begin{gathered}
E\left(\beta_{1}\right)=\frac{n \alpha+\alpha^{\prime}}{\beta^{\prime}+\sum_{i=1}^{n} x_{i}} . \\
\operatorname{Var}\left(\beta_{1}\right)=\frac{n \alpha+\alpha^{\prime}}{\left(\beta^{\prime}+\sum_{i=1}^{n} x_{i}\right)^{2}} .
\end{gathered}
$$

Berdasarkan Definisi (2.3), maka posterior min merupakan penduga Bayes untuk parameter $\beta_{1}$, maka $\beta_{1}=\frac{n \alpha+\alpha^{\prime}}{\beta^{\prime}+\sum_{i=1}^{n} x_{i}}$.

\subsubsection{Posterior Nilai Tengah dan Posterior Variansi dari Distribusi Prior Konjugat}

Distribusi posterior yang diperoleh adalah berdistribusi $\beta_{2} \mid X \sim G A M(n \alpha-2 k+$ $\left.1, \sum_{i=1}^{n} x_{i}\right)$, maka posterior nilai tengah dan posterior variansi untuk parameter $\beta_{2}$ adalah

$$
\begin{gathered}
E\left(\beta_{2}\right)=\frac{n \alpha-2 k+1}{\left(\sum_{i=1}^{n} x_{i}\right)} . \\
\operatorname{Var}\left(\beta_{2}\right)=\frac{n \alpha-2 k+1}{\left(\sum_{i=1}^{n} x_{i}\right)^{2}} .
\end{gathered}
$$

Berdasarkan Definisi (2.3), posterior nilai tengah merupakan penduga Bayes untuk parameter $\beta_{2}$, maka $\beta_{2}=\frac{n \alpha-2 k+1}{\left(\sum_{i=1}^{n} x_{i}\right)}$. 


\section{Kesimpulan}

Setelah dilakukan pembahasan maka diperoleh beberapa kesimpulan, yaitu:

(1) Distribusi posterior yang dihasilkan dengan menggunakan distribusi prior konjugat adalah distribusi $\operatorname{Gamma}(\alpha ", \beta ")$ dengan $\alpha^{\prime \prime}=n \alpha+r \operatorname{dan} \beta^{\prime \prime}=$ $v+\sum_{i=1}^{n} x_{i}$ dan menghasilkan pendugaan parameter $\hat{\beta}_{1}=\frac{n \alpha+\alpha^{\prime}}{\beta^{\prime}+\sum_{i=1}^{n} x_{i}}$.

(2) Distribusi posterior yang dihasilkan dengan menggunakan distribusi prior noninformatif adalah distribusi $\operatorname{Gamma}\left(\alpha^{\prime}, \beta^{\prime}\right)$ dengan $\alpha^{\prime}=n \alpha-2 k+1$ dan $\beta^{\prime}=$ $\sum_{i=1}^{n} x_{i}$ dan menghasilkan pendugaan parameter $\hat{\beta}_{2}=\frac{n \alpha-2 k+1}{\left(\sum_{i=1}^{n} x_{i}\right)}$.

\section{Ucapan Terima kasih}

Penulis mengucapkan terima kasih kepada Bapak Yudiantri Asdi, Ibu Maiyastri, dan ibu Lyra Yulianti yang telah memberikan masukan dan saran sehingga makalah ini dapat diselesaikan dengan baik.

\section{Daftar Pustaka}

[1] Al-Kutubi, H.S., N.A. Ibrahim. 2009. Bayes Estimator for Exponential Distribution with Extension of Jeffery Prior Information. Malaysia Journa of Mathematical Sciences. 3(2): $297-313$

[2] Apsari, W.,H. Yasin, Sugito. 2013. Estimasi Parameter Regresi Logistik Multinomial Dengan Metode Bayes Jurnal Gaussian. 2(1): 79 - 88

[3] Bain, L.J. dan M. Engelhardt. 1992. Introduction to Probability and Mathematical Statistic.Second Edision. Duxbury Press, California.

[4] Bolstad, W.M. 2007. Introduction to Bayesian Statistics.Second Edition. John Wiley and Sons, America.

[5] Box, G.E.P. dan G.C. Tiao. 1973. Bayesian Inference in Statistical Analysis.. Second Edition. Addison-Wesley Publishing Company, London

[6] Burnham, P.K. dan D.R. Anderson. 2002. Model Selection and Multimodel Inference: A Pratical Information-Theoretic Approach. Second Edition. SpringerVerlag, New York

[7] Casella, G dan R.L. Berger. 2001. Statistical Inference. Second Edition. Pacific Grove, California

[8] Son, Y.S. dan M. Oh. 2006. Bayesian Estimation of The Two-Parameter Gamma Distribution. Communications in Statistics: Simulation and Computation. 35: $285-293$

[9] Walpole, R.E. 1986. Pengantar Statistika. Edisi Ketiga. PT Gramedia Pustaka Utama, Jakarta

[10] Walpole, R.E dan Myers, R.H. 1995. Ilmu Peluang dan Statistika untuk Insinyur and Ilmuwan. Edisi Keempat. ITB, Bandung

[11] Wijayanto, H. 2015. Pendekatan Kemungkinan Maksimum dan Bayes untuk Pendugaan Produktivitas Komoditas Hortikultura. Disertasi S-3, tidak diterbitkan, IPB Bogor 